\title{
The problem of the national image of Russia in the interpretation of Chinese scientists
}

\author{
Zhou Xie ${ }^{1}$, Zeming Zhang ${ }^{1}$
}

\begin{tabular}{lr}
\hline${ }^{1}$ Southwest University, Chongqing, China & \\
\hline DOI: 10.18255/2412-6519-2021-3-256-269 & Research Article \\
& Full text in Russian
\end{tabular}

The article examines the main trends in the study of the theory of national image by Chinese scientists and the problems of the national image of Russia in the eyes of the PRC public, discusses the prerequisites for the study of the theory of national image, compares the definitions of Chinese scientists, examines their contribution to the theory of national image and the evolution of the national image of Russia in the consciousness of Chinese society in the period from the formation of the PRC to the end of the first decade of the XXI century. The authors state that the national image of Russia in China is formed under the influence of many factors (the political situation in Russia and China, the state of bilateral relations, the degree of awareness in China about Russia) and come to the conclusion that a positive image can improve relations between the two countries. Studying the Chinese perception of the national image of Russia will allow you to learn about the values, moral norms, psychology and mentality of the Chinese themselves. In addition, the transformation of Russia's national image in China depends not only on the changes in Russia and the complex bilateral relations of both countries, but also reflects social changes in China. The improvement of Russia's national image in China contributes to the development of strategic partnership and cooperation between the two countries and the stability of bilateral relations, allows it to increase its "soft power". Creating harmonious relations between countries, strengthening mutual trust, expanding economic and trade exchanges and cultural exchanges are important ways to create a positive and bright national image.

Keywords: Russian-Chinese relations; national image; "soft power"; "hard power"; public opinion; image formation

INFORMATION ABOUT THE AUTHORS

\begin{tabular}{r|l} 
Xie, Zhou & E-mail: xiezhou1234@163.com \\
(correspondence author) & ORCID 0000-0001-8753-7182 \\
& Doc. Sc. (Philology), Professor, director of the center for Russian-Speaking \\
& Countries Studies in SWU at the Ministry of Education of the People's \\
& Republic of China, Dean of the Faculty of the Russian Language of the \\
& Institute of Foreign Languages of Southwest University in Chongqing.
\end{tabular}

Zhang, Zeming | E-mail: 745725097@qq.com ORCID 0000-0002-6692-544X

Master Degree Candidate of the Southwest University Southwest

University

Funding: Center for Russian-Speaking Countries Studies of the Southwest University under the Ministry of Education of the People's Republic of China.

For citation: Xie Zhou, Zhang Zeming The problem of the national image of Russia in the interpretation of Chinese scientists // Social'nye i gumanitarnye znanija. 2021. Vol. 7, No 3. P. 256-269. (in Russ.)

(C) Xie Zhou, Zhang Zeming, 2021

This is an open access article under the CC BY license (https://creativecommons.org/licenses/by/4.0/) 


\title{
Проблема национального имиджа России в интерпретации китайских ученых
}

\author{
Чжоу $\mathrm{Ce}^{1}$, Цзэмин Чжан ${ }^{1}$
}

1Юго-Западный университет, ул. Тяньшэн, д. 2, район Бэйбэй, Чунцин, 400715, КНР

DOI: $10.18255 / 2412-6519-2021-3-256-269$

УдК 301.085(510)(092)

Научная статья

Полный текст на русском языке

В статье рассматриваются основные тенденции в изучении китайскими учеными теории национального имиджа и проблем национального имиджа России в глазах общественности КНР, обсуждаются предпосылки исследования теории национального имиджа, сопоставляются определения китайских ученых, рассматривается их вклад в теорию национального имиджа и эволюция национального имиджа России в сознании китайского общества в период с образования КНР до конца первого десятилетия XXI в. Авторы констатируют, что национальный имидж России в Китае складывается под воздействием множества факторов (политическая ситуация в России и Китае, состояние двусторонних отношений, степень осведомлённости в Китае о России), и приходят к выводу, что положительный имидж может улучшить отношения между двумя странами. Изучение представления китайцев о национальном имидже России позволит узнать о ценностях, моральных нормах, психологии и менталитете самих китайцев. Кроме того, трансформация национального имиджа России в Китае не только зависит от изменения России и сложных двусторонних отношений обеих стран, но и отражает социальные изменения в Китае. Улучшение национального имиджа России в Китае способствует развитию стратегического партнерства и сотрудничества между двумя странами и стабильности двусторонних отношений, позволяет нарастить свою «мягкую силу». Создание гармоничных отношений между странами, укрепление взаимного доверия, расширение экономических и торговых обменов и культурных обменов - важные способы создания позитивного и яркого национального имиджа.

Ключевые слова: российско-китайские отношения; национальный имидж; «мягкая сила»; «жёсткая сила»; общественное мнение; формирование имиджа

ИНФОРМАЦИЯ ОБ АВТОРАХ

\begin{tabular}{|c|c|}
\hline $\begin{array}{r}\text { Се, Чжоу } \\
\text { (автор для корреспонденции) }\end{array}$ & $\begin{array}{l}\text { E-mail: xiezhou1234@163.com } \\
\text { ORCID 0000-0001-8753-7182 } \\
\text { Доктор филологических наук, профессор, директор Центра } \\
\text { по изучению русскоговорящих стран (ЦИРС) Юго-Западного } \\
\text { университета при Министерстве образования КНР, декан } \\
\text { факультета русского языка Института иностранных языков } \\
\text { Юго-Западного университета }\end{array}$ \\
\hline Чжан, Цзэмин & $\begin{array}{l}\text { E-mail: 745725097@qq.com } \\
\text { ORCID 0000-0002-6692-544X } \\
\text { Магистрант Юго-Западного университета }\end{array}$ \\
\hline
\end{tabular}

Финансирование: Центр по изучению русскоговорящих стран (ЦИРС) Юго-Западного университета КНР при Министерстве образования Китайской Народной Республики.

Для цитирования: Се Чжоу, Чжан Цзэмин Проблема национального имиджа России в интерпретации китайских ученых // Социальные и гуманитарные знания. 2021. Том 7, № 3. С. 256-269. 


\section{1. Введение. Предпосылки изучения национального имиджа}

С развитием науки и техники в современную эпоху глобализации конкуренция государств за всестороннюю национальную силу становится все более жесткой. Укрепление всеобъемлющей национальной мощи неотделимо от укрепления так называемой национальной «мягкой силы». И этот процесс является важным аспектом для конкуренции стран на мировой арене. В качестве важной части «мягкой силы» национальный имидж привлекает к себе все большее внимание в разных странах. Американский ученый Джошуа Купер Ремо (Joshua Cooper Ramo) отметил, что «хороший национальный имидж может снизить огромные трения до маленьких масштабов, в то время как плохой национальный имидж может в несколько раз усилить конфликты. Национальный имидж с непоследовательными внутренними и внешними стратегиями также приведет к аналогичным результатам, что приведет к увеличению рисков» [1, с. 23] (здесь и далее перевод наш - С.Ч., Ч.Ц). Китайский учёный Ли Вэй считает, что «хороший имидж страны и «мягкая сила» страны будут играть позитивную роль в содействии пониманию и доверию, признанию и поддержке других стран и установлению долгосрочных дружественных национальных отношений с другими государствами; в противном случае, негативный национальный имидж сделает восприятие и оценку людьми всей соответствующей информации и поведения этой страны и ее народа намеренно или непреднамеренно враждебными».[2, с. 2] Таким образом, с одной стороны, национальный имидж играет важную роль в улучшении «мягкой силы» страны. С другой стороны, качество национального имиджа также будет влиять на долгосрочное развитие международных отношений и распространение иностранной культуры. Исходя из этого, китайские учёные-политологи уделяют все больше внимания изучению проблемы «национального имиджа», углубленному обсуждению того, как формировать и распространять свой собственный имидж, понимать и принимать национальные имиджи других стран.

Как развивающаяся дисциплина имиджелогия впервые появилась в Европе в прошлом веке и актуализировала широкий спектр исследований, касающихся психологии восприятия имиджа, разнообразных методов наблюдения, когнитивных функций имиджа, знаков и символов имиджа, коллективного бессознательного, идеологии, исторических концепций, иерархических отношений, типов мышления, языков, художественной литературы, теорий воображения и т. д. Французский ученый Даниэль-Анри Пажо объяснял это следующим образом: «Имиджелогия не ограничивается изучением литературного замещения того, что называется просто «реальностью». Она должна изучать, как различные образы образуют конкретные описания в определенный исторический период, и изучать линии власти, которые управляют общим воображением общества и его литературной системой» [3, с. 154].

В настоящее время исследование «национального имиджа» стало актуальной темой для китайских ученых, которые активно изучают исследования российских и западных политологов, посвященные данной проблеме, и разрабатывают свои концепции структуры национального имиджа. 


\section{2. Концепция и структура национального имиджа}

Национальный имидж - это комплекс различных аспектов деятельности страны. Качество национального имиджа влияет на статус страны на международной арене, а также на внешнюю политику других стран в отношении с этой страной. Еще в начале 1970-х годов ученый Кембриджского университета Элан Кельман (Ilan Kelman) отметил, что «исследования в области принятия решений во внешней политике должны проводиться в более широком контексте национального имиджа» [4, с. 1]. Важность национального имиджа очевидна: западные ученые начали обсуждение «национальной репутации», «международного престижа» и «национальной идентичности» очень рано, а позже появился термин «национальный имидж», но унифицированного значения для понятия национального имиджа исследователи еще не выработали. Хотя китайские ученые позднее начали изучение данной проблемы, они разработали множество разнообразных и взаимосвязанных концепций, представляющих разные точки зрения на сущность национального имиджа. Китайский ученый Ли Шоуюань в своей книге «Международные отношения и китайская дипломатия - уникальный ландшафт СМИ», основываясь на внешних факторах, определил национальный имидж так: «Форма и внешний вид суверенной страны и нации в мире и общественное мнение в международной среде» [5, с. 305]. Гуань Вэньху дал следующее определение национального имиджа в «Теории национального имиджа»: «Национальный имидж носит комплексный характер, и это общая оценка и выявление специфики внешней и внутренней общественности страны в отношении самой страны, поведения государства, деятельности страны и ее результатов» [6, с. 23]. Ли Яньбин в своей книге «Построение национального имиджа Китая в перспективе политической коммуникации» предлагает такое определение данного понятия: «Это субъективное восприятие страны людьми на основе объективной реальности страны и результат передачи этого восприятия через средства массовой информации» [7, с. 26].

Значительное количество ученых рассматривают концепцию национального имиджа с международной точки зрения. Так, Ян Вэйфэнь считает, что национальный имидж является «общей оценкой широкой публикой относительной стабильности страны» $[8$, c. 25]. Чжан Кунь в своей книге «Национальная имиджевая коммуникация» констатирует, что «национальный имидж - это проекция различных объективных условий страны в общественном мнении международного сообщества, отражение характеристик национального поведения, «духовного облика» страны в сознании международного сообщества и общая оценка соответствующей страны общественностью» [9, с. 180].

Все вышеприведенные определения национального имиджа свидетельствуют о том, что интерпретация исследователями данного феномена осуществляется в основном в аспектах внешних показателей национальной силы (политика, экономика, вооруженные силы и т.д.) и внутреннего проявления национальной силы (культура, традиции, национальный дух, воля и т. д.), которые ученые называют «твёрдой силой» и «мягкой силой».

Что касается направленности национального имиджа, то вышеупомянутые исследователи придерживаются почти одинаковых взглядов. Большинство учёных считает, что национальный имидж - это реакция, оценка, идентификация и восприятие людьми своей страны и других стран. Однако некоторые учёные сводят 
направленность национального имиджа к «национальному менталитету и воле» и рассматривают его с иной точки зрения. Китайский ученый Чэн Манли пишет об этом так: «Национальный имидж - это субъективное сознание и «точка вспышки» в национальном или государственном духе. Он основан на исторических и культурных традициях, интегрирован с современными элементами, извлечен и усовершенствован, и является концентрированным выражением национального духа и воли» $[10$, с. 5$]$.

Исходя из всего вышесказанного, очевидно, что для китайских политологов понятие национального имиджа складывается из следующих аспектов:

1. Национальный имидж - это целостный и комплексный имидж страны.

2. Необходимо рассматривать национальный имидж в международном сообществе и исследовать имидж иностранных государств.

3. Национальный имидж относительно стабилен в течение определенного периода времени.

4. Существует частичное совпадение национального имиджа и национальной мощи, но они не равны. Национальная мощь подчеркивает совокупность национальной силы во всех аспектах, а национальный имидж подчеркивает впечатление от страны у людей других стран. Национальная мощь - это объект; национальный имидж - тень, отражающая мягкую силу страны. Национальная мощь отражена в национальном имидже, но в то же время национальный имидж может стать компонентом расширения национальной мощи.

5. Национальный имидж должен включать политические, экономические, военные, культурные, географические, исторические, традиционные и другие факторы. Внешняя оценка страны может исходить из одного фактора или нескольких факторов. Например, страна может рассматриваться как демократическое или централизованное государство, как развитая или отсталая страна, в зависимости от точки зрения людей. Обычный человек может уделять больше внимания экономике и культуре оцениваемой страны, в то время как военный может уделять больше внимания вооруженным силам оцениваемой страны, а государственные служащие и чиновники могут уделять больше внимания политике и политической системе оцениваемой страны. Что касается ученых, то они должны оценивать страну всесторонне.

6. Одни элементы, которые составляют имидж страны, являются константными, другие - переменными, третьи могут быть и постоянными, и переменными. Множество различных факторов оказывает влияние на формирование образа страны. Китайские ученые вслед за профессором Э. А. Галумовым выделяют три группы факторов, влияющих на формирование имиджа страны. Первая из них почти не поддается манипуляции, а две другие могут корректироваться.

1. «Условно-статичные» факторы формирования образа государства.

2. «Корректируемые условно-динамичные» социологические факторы.

3. «Корректируемые условно-динамичные» институциональные факторы [11, c. 202].

Образ государства складывается из «объективных», «постоянных» факторов (географическое положение, площадь государства, территориальные границы, выход к морям и т. п.). Также сюда можно отнести культурное и национальное наследие страны, исторические события, имена выдающихся деятелей, которые вошли в историю государства. К следующей группе факторов, формирующих образ 
страны, относятся социально-психологические настроения общества, общественно-политическая интеграция населения, моральное и нравственное развитие людей. Институциональные факторы характеризуются устойчивостью экономики (в эту группу входят показатели ВВП, уровень доходов на душу населения, привлекаемые инвестиции и др.), соответствием правовых норм международным требованиям, механизмами государственного регулирования. Улучшение и изменение национального имиджа во многом зависит от изменения переменных элементов.

На основе анализа вышеперечисленных проблем можно определить национальный имидж как сложившуюся в массовом сознании устойчивую совокупность рациональных и эмоциональных представлений о стране, формирующихся у людей на основе собственного опыта и имеющейся информации, полученной из различных источников.

Понятие, тесно связанное с национальным имиджем, - это «структурная модель имиджа страны». Структурные элементы имиджа страны включают географию, жителей, культуру, традиции, политическую систему, стратегические цели и другие аспекты. Некоторые из этих элементов постоянны и в основном остаются неизменными, другие являются переменными, но они остаются неизменными в течение определенного периода времени. Если эти элементы останутся в основном неизменными, национальный имидж обретет относительно стабильную структуру. Например, структурный элемент имиджа Китая «Китай - это страна с большим населением» основан на объективных фактах и поэтому в основном стабилен. Структурный элемент «Китай является социалистической страной» или, как часто говорят на Западе, «Китай является коммунистической страной» также основан на объективных факторах, отражая реальную ситуацию: Китай не является капиталистической страной и не имеет демократии западного образца. Сегодня, когда социализм и капитализм по-прежнему противостоят друг другу, базовое понимание социализма или коммунистического Китая на Западе кардинально не изменится. В глазах представителей Запада «социалистический Китай» или «коммунистический Китай» - это устойчивые элементы структурной модели национального имиджа Китая. Другим примером является структурная модель имиджа России в Китае. Большинство китайцев считает, что «Россия - это западная страна», и этот компонент структуры национального имиджа оказывает решающее влияние на общий имидж страны.

\section{3. Исследование теории национального имиджа в Китае}

Исследования национального имиджа в Китае и за рубежом проводились достаточно активно и имели хорошие результаты, многие исследования дали инновационные и ценные результаты в области изучения национального имиджа. Основные исследования национального имиджа в основном сосредоточены на его концептуальном осмыслении и сущностных характеристиках.

В Китае данная область науки фокусируется на таких областях, как журналистика и коммуникация, международные отношения и политика. Сюй Сяогэ был первым ученым, который обратил внимание на проблему национального имиджа, его определение национального имиджа относится к категории медиаимиджа. Он считает, что национальный имидж - это «образ, сформированный страной 
в международном потоке новостей, или имидж страны в новостных и речевых отчетах других стран» [12, с. 35]. Гуань Вэньху как ученый, специализирующийся на исследованиях национального имиджа, опубликовал книгу «Теория национального имиджа», и данное им в этой книге определение национального имиджа имеет большое влияние в академической среде. Учёный считает, что национальный имидж является комплексным и представляет собой общую оценку и признание мнения народа страны о политике, деятельности страны и ее результатах [6, с. 23-24]. Анализируя структурную модель национального имиджа, китайский политолог Ли Чжи утверждает, что имидж страны - это продукт, созданный («структурированный») в долгосрочном и постоянном взаимодействии между отечеством и другими странами [13, с. 25]. Ян Вэйфэнь определил национальный имидж как «общую оценку относительной стабильности государства международной широкой общественностью» [8, с. 25]. Это определение похоже на точку зрения Тан Гуанхуна: «Национальный имидж - это общая и социальная оценка страны внешней и внутренней общественностью» [14, с. 19].

В исследованиях китайских ученых теория национального имиджа в основном изучается в следующих трех аспектах:

Академическая интерпретация и исследования на макро-стратегическом уровне построения национального имиджа. Вот примеры некоторых определений или заглавий статей китайских политологов. Хэ Хуэй: «Создание национального имиджа в новой медиа-среде должно соответствовать закону о коммуникации» [15, с. 45], Чен Манли: «Массовая коммуникация и формирование национального имиджа» [16, с. 6], Лю Хуэй: «Создание национального имиджа: невыносимый вес массовой коммуникации»[17, с. 46], и Сяо Чуньфэн: «Визуальная коммуникация национального имиджа в эпоху всех медиа» [18, с. 124]. Все эти утверждения ориентированы на новую ситуацию построения национального имиджа и выдвигают государственные стратегии, которые помогают реализовать и использовать имидж страны. В определенной степени это дальнейшая систематизация теории построения национального имиджа для руководства практикой построения национального имиджа.

Углубление и интерпретация теоретического когнитивного уровня построения национального имиджа. Китаю, который первоначально сосредоточился на «твёрдой» пропаганде и развитии «твёрдой» силы национального имиджа, необходимо иметь более систематическое и научное понимание «мягкой» тенденции построения национального имиджа в новую эпоху, чтобы руководить крупномасштабными ответственными практиками. Ученые усвоили зарубежные передовые теории построения национального имиджа, а также объединили их с типичными китайскими установками, чтобы создать собственную уникальную систему теории построения национального имиджа в Китае, что нашло отражение в исследованиях Чжана Куна «Обсуждение национального имиджа» и Чжао Сюебо «Понимание концепции национального имиджа».

Акцент на оперативном уровне построения национального имиджа и выдвижении соответствующих контрмер для решения конкретных проблем. Модель мирового общения и коммуникации продолжает развиваться и обновляться. Создание национального имиджа должно быть оптимизировано различными способами. И в этом отношении китайские ученые предпринимают анализ конкретных собы- 
тий или исследовательских объектов, чтобы решить некоторые локальные проблемы, выявив таким образом универсальные принципы, этому посвящены множество работ китайских политологов: Ли Цзяньсинь, Ли Синвэй «Создание имиджа китайской инициативы «Один пояс, один путь» в сообщениях российских СМИ»; О. А. Бакулин, Шэнь Син: «Имидж Китая в российских средствах массовой информации на примере Олимпийских игр в Пекине»; Сюй Хуа «Проблемы национального имиджа современной России»; Ке Хуэйсинь «Российский национальный имидж в китайских СМИ: анализ содержания «Молодежной ежедневной газеты Китая» и т. д.

\section{4. Исследование национального имиджа России в Китае}

Имидж России в Китае представляет собой относительно стабильную общую оценку России (Советского Союза) китайским народом, отражающую китайское восприятие России и взгляды Китая на Россию. Несомненно, это новый и важный аспект для изучения китайско-российских отношений.

Академик С. Л. Тихвинский, один из самых авторитетных советских и российских китаеведов второй половины XX - начала XXI века, еще в 2008 году опубликовал свою книгу «Восприятие в Китае образа России» $[19$, с. 244]. Это исследование содержит первый подробный обзор эволюции имиджа России в Китае с XVII по начало XXI века. Однако следует отметить, что, поскольку академик Тихвинский занимал пост заместителя министра иностранных дел Советского Союза во время китайско-советской конфронтации, он получил большой опыт в китайско-советских дебатах. Поэтому эта книга несколько односторонне показывает отношения между двумя странами, в ней множество предрассудков, резких заявлений по отношению к Китаю, сильна авторская симпатия по отношению к Советскому Союзу. Кроме того, эта книга не объясняет, а порой игнорирует некоторые проблемы.

Попытку разрешения этих проблем осуществил в своем исследовании А. В. Лукин, изучавший имидж России в Китае в одно время с академиком С. Л. Тихвинским. В 2007 году А. В. Лукин опубликовал свою книгу «Медведь наблюдает за драконом. Образ Китая в России в XVII-XX веках» [20, с. 675]. Книга, написанная на основе сбора большого количества исторических материалов, представляет, обсуждает и оценивает эволюцию китайского имиджа в России с XVII по XX век на основе большого количества исторических данных и пытается объяснить влияние этого образа на внутреннюю и внешнюю политику России с точки зрения истории и современного состояния китайско-российских отношений. В то же время автор рассматривает эволюцию имиджа Китая в России в качестве примера для обсуждения развития и изменения российских политических концепций. В исследовании также анализируются исторические противоречия восприятия Китая в России, сделана попытка объективно отразить реальное состояние китайско-советских и китайско-российских отношений в исторических условиях той или иной эпохи.

Очевидно, что исследования проблемы имиджа России в Китае, предпринятые русскими учеными, опережают работы китайских политологов по аналогичной проблематике. Тем не менее в последние годы в связи с постоянным развитием китайско-российских отношений в академических кругах Китая постепенно усиливается изучение национального имиджа России, и в этой области уже существует множество результатов исследований. 
Одно из ключевых исследований в этом направлении - «Образ России в Китае (1949-2009)» китайского русиста Ли Суйаня, где всесторонне анализируются изменения в представлении об имидже России в Китае и взаимное непонимание между Китаем и Россией. Автор использует статьи в СМИ, научные публикации в Китае и России, интернет-источники - блоги, форумы - и даже стихи китайских поэтов и выделяет в эволюции образа России в Китае за эти 60 лет три этапа: «положительный образ («медовый период» 1949 - начало 1960-х), отрицательный образ (период противостояния, начало 1960-х - 1989 год), относительно объективный образ (с 1989 г. - по время написания книги)» [21, с. 479]. Анализируя образ России (Советского Союза) на каждом этапе, автор исходит из следующих аспектов: отношения между двумя странами на данном этапе; какой образ России (Советского Союза) Китай хочет сформировать и как его формировать; каков образ России (Советского Союза) в китайских учебниках; каков образ России (Советского Союза) в китайских литературных произведениях; какова сущность «советского комплекса» в сознании китайцев.

В работах китайских политологов, посвященных исследованию имиджа России в Китае, выделяются следующие направления. В ряде работ рассматривается политический имидж России с момента распада Советского Союза до нынешнего этапа, анализируется, как Россия использует свой имидж великой державы в сложной ситуации на международной арене, обсуждается проблема национального имиджа России на политическом уровне (Ли Суйань «Изменение русского имиджа в Китае за последние полвека», Ян Цин: «Эволюция русского имиджа в Китае с точки зрения конструктивизма» и Сюй Хуа: «Проблема современного имиджа России»). В других работах производится анализ имиджа России в Китае с опорой на китайские СМИ, главным образом на такие издания, как «Жэньминь Жибао (The People's Daily)» и «Китайская молодежная газета (China Youth Daily)», в этих исследованиях рассматриваются репортажи о России в течение нескольких лет и объективно анализируется внутреннее восприятие Китаем национального имиджа России в политической, военной и других областях, связанных с национальной безопасностью (Чжуан Янь «Анализ российских репортажей в основных китайских СМИ», Ке Хуэйсинь «Российский национальный имидж в китайских СМИ»). Третья группа исследований ориентирована на восприятие российского национального имиджа в Китае, основанного на опросах общественного мнения: «Исследование дружественных отношений между Китаем и Россией» Пан Дели и «Образ другой страны в глазах китайской и российской молодежи» Ян Синьмо. В первой статье описан и проанализирован опрос общественного мнения людей в некоторых районах Китая под названием «Россия глазами китайского народа». Другая статья анализирует национальный имидж России в глазах китайского народа на основе анкетного опроса 2008 года о том, как видят Китай молодые жители российского Дальнего Востока. Несмотря на то, что оба исследования основаны на опросах общественного мнения, очевидно, что фокусы исследований различны, выбраны различные типы электората и сделанные в работах выводы не универсальны в силу ограниченности выбора регионов.

Вышеназванные работы обсуждают текущее состояние и проблемы национального имиджа России с разных точек зрения. Некоторые ученые излагают свои собственные взгляды относительно продвижения и распространения национального имиджа, другие систематически анализируют, как Россия распространяет свой 
национальный имидж. По мере углубления исследований национального имиджа России достижения российской национальной имиджевой коммуникации будут постепенно расти, а конкретные стратегии и эффекты ее национальной имиджевой коммуникации будут постепенно становиться более понятными в ходе непрерывного обсуждения в академическом сообществе.

\section{5. Изменения специфики национального имиджа России в Китае}

В структуре национального имиджа можно выделить внутренний имидж и внешний, международный имидж. Основное различие внешнего и внутреннего имиджа - это аудитория, с которой осуществляются коммуникации Внутренний имидж - это представление страны о себе, он формируется в общественном мнении граждан этой страны и включает в себя национальную идентичность, статус государства в международной среде, ситуативные образы, привносимые правительством, которые транслируются широкой общественности. Внешний имидж это представление о стране, которое складывается у населения других государств. Основными проводниками имиджа страны за рубежом выступают субъекты международных сфер: дипломатии, внешнеэкономической деятельности (включая финансовую сферу), туризма, транспорта, гостиничного дела и другие. За прошедшее столетие имидж России в китайских СМИ пережил эволюцию, отраженную в таких формулах, как «СССР - старший брат», «Советский ревизионизм», «Страна в хаосе и упадке после распада СССР», «Стратегический партнер» и «Всеобъемлющее партнерство и стратегическое взаимодействие в новую эпоху». Каждый вариант имиджа, который полностью представлен в китайских СМИ, является проявлением русско-китайских двусторонних отношений в международной системе, а также демонстрирует эволюцию этих отношений в условиях смены исторических парадигм.

\section{1. «Старший брат»: положительный имидж}

На протяжении XX века имидж «Советский Союз как старший брат» или как глава большой социалистической семьи существовал в Китае в течение почти пятидесяти лет, с 1949 г. до начала 1960-х гг., и по праву может считаться самым выдающимся вариантом русского имиджа в глазах китайского народа в прошлом веке. В 1949 году Коммунистическая партия создала Новый Китай, а китайское правительство осуществило внешнюю политику «склонения в сторону» к Советскому Союзу. С подписанием «Советско-китайского договора о дружбе и взаимной помощи» имидж «Старший брат» появился у Советского Союза прежде всего в средствах массовой информации. В журнале «Народная литература» с 1949 по 1959 годы авторы публикаций часто использовали такие слова, как «счастливая страна и счастливые люди», «богатая страна», «рай», «большой брат» и «великий», чтобы описать позитивный имидж «СССР - старший брат».

\section{2. «Советский ревизионизм»: имидж СССР после разрыва между СССР и Китаем}

В 1956 году после 20-го съезда Коммунистической партии Советского Союза китайско-советские отношения начали ухудшаться, и в 1958 году Советский Союз 
выступил против Великой китайской коммунистической кампании «Большой скачок». В 1969 году между Китаем и Советским Союзом произошел вооруженный пограничный конфликт на острове Чжэньбао (Даманский остров). После этих событий отношения между Китаем и Советским Союзом были полностью разрушены. Имидж «Старший брат» сменился противоположным: «Советский ревизионизм», «Повстанческая группа советских ревизионистов» и «Социальный империализм» стали репрезентативными словами национального имиджа Советского Союза в Китае. В то время в китайских СМИ было слишком много сильных оскорбительных высказываний против Советского Союза, позиционируемого как сверхдержава, угрожающая безопасности Китая. Это видно из заголовков соответствующих сообщений в печатных СМИ Китая с 1960 по 1980 годы: «Сговор между СССР и США в соответствующих учреждениях ООН», «Советский ревизионизм сломался и перевернулся», «Как Советский Союз выродился и стал социал-империалистической страной», «Ревизионистский Советский Союз - это бумажный тигр» и т. д. Такой же характер носили и культурные обзоры, как, например, в статье «Современные ревизионистские образцы искусства - фильмы Г. Чухрая» [22, с. 11], и так далее. В этот период слова «обратное и неправильное», «откровенная ложь», «бесстыдный» и «абсурдный» были общими словами, использовавшимися в статьях для критики Советского Союза. Говоря о лидерах Советского Союза, вкитайская пресса тех лет называло их «лидерами советского ревизионизма».

\section{3. «Хаотичная и постепенно слабеющая страна»: имидж России после распада СССР}

В течение 10 лет после распада Советского Союза в конце XX века «Хаотичная и постепенно слабая страна» и «Нестабильная и спорная страна» были основными характеристиками имиджа России в китайских СМИ. В конце 1980-х годов с восстановлением китайско-советских отношений имидж «Советский ревизионизм» в китайских СМИ больше не существовал. После распада Советского Союза имидж России в Китае постепенно ухудшался, чему способствовала социально-политическая обстановка в стране: конфликт России и Украины из-за Крыма; гражданские войны в Грузии и Молдове; конфликты в Центральной Азии; две чеченские войны, рост организованной преступности, террористические акты и т. д. Однако с учетом идеологических факторов и объективной силы России имидж России в восприятии Китая имел и свои положительные стороны: люди классифицировали Россию как одну из «наиболее сильных» стран: «Ни одна страна в мире не может игнорировать существование России и ее большое влияние, несмотря на ее временный упадок» $[23$, c. 74$]$.

\section{4. «Россия - дружеский партнер по стратегическому взаимодействию»: объективный имидж России в конце XX - начале XXI века}

В конце XX - начале XXI века двусторонние отношения между Россией и Китаем активно развиваются, и российский национальный имидж, представленный в китайских СМИ, приобретает позитивные характеристики (в отличие от негативного имиджа России в США и других западных странах, характеризуемого опреде- 
лениями «Регресс демократии» и «Авторитаризм) и определяется формулой «Стратегический партнер». Китайское правительство и ученые считают, что «контролируемая государством демократия» и «контролируемая государством рыночная экономика» соответствуют ее национальным условиям. «С одной стороны, для России невозможно иметь такую форму демократии, как в западных странах; с другой стороны, Россия не может повторить ошибку прежнего политического хаоса и пожертвовать экономическим развитием для политической борьбы, следовательно, установление относительно централизованной «управляемой демократии» может быть лучшим выбором для страны» [24, с. 65].

Таким образом, китайские ученые, изучающие эволюцию национального имиджа России в глазах общественности КНР, приходят к выводу, что он складывается под воздействием множества факторов (политическая ситуация в России и Китае, состояние двусторонних отношений, степень осведомлённости в Китае о России), положительный имидж может улучшить отношения между двумя странами. Кроме того, изучение представлений китайцев о национальном имидже России позволит узнать о ценностях, моральных нормах, психологии и менталитете самих китайцев, иначе говоря, трансформация национального имиджа России в Китае не только зависит от изменения России и сложных двусторонних отношений обеих стран, но и отражает социальные изменения в Китае, собственное развитие китайцев.

\section{Заключение}

В 2019 году исполнилось 70 лет со дня установления дипломатических отношений между двумя странами, и это событие торжественно отмечалось в России и Китае. Председатель Китайской Народной Республики Си Цзиньпин по приглашению Президента Российской Федерации В. В. Путина с 5 по 7 июня 2019 года посетил Российскую Федерацию с государственным визитом и принял участие в XXIII Петербургском международном экономическом форуме. В Москве состоялись переговоры глав государств, а также встреча Председателя Китайской Народной Республики Си Цзиньпина с Председателем Правительства Российской Федерации Д. А. Медведевым. В «Совместном заявлении Российской Федерации и Китайской Народной Республики о развитии отношений всеобъемлющего партнерства и стратегического взаимодействия, вступающих в новую эпоху» говорилось о том, что российско-китайские отношения вышли на самый высокий уровень, демонстрируя пример добрососедского сосуществования и взаимовыгодного сотрудничества, они являются устойчивыми и стабильными, не подвержены влиянию извне, обладают огромным внутренним потенциалом, имеют широкие перспективы развития и характеризуются:

- высокой степенью политического доверия;

- насыщенными контактами на высшем и высоком уровнях, разнообразными механизмами сотрудничества в различных областях;

- богатым по содержанию и стратегическим по значению практическим взаимодействием;

- прочной общественной базой двусторонних отношений, опирающихся на традиции дружбы между народами России и Китая, передаваемой из поколения в поколение; 
- тесной и эффективной координацией на международной арене [25, с. 2].

Улучшение национального имиджа России в Китае способствует развитию стратегического партнерства и сотрудничества между двумя странами и стабильности двусторонних отношений. Активное участие России и Китая в деятельности по формированию своего положительного образа в другой стране позволяет нарастить свою «мягкую силу» и развить двусторонние отношения. Создание гармоничных отношений между странами, укрепление взаимного доверия, расширение экономических и торговых обменов и культурных обменов - важные способы создания позитивного и яркого национального имиджа, это сложный и планомерный проект, требующий совместных усилий России и Китая.

\section{Ссылки / References}

1. Образ Китая: Китай глазами зарубежных ученых / Джошуа Купер Ремер и др.; перевод Шен Сяолей. Пекин: Social Sciences Archives Press, 2008. 360 с. (на кит. языке).

2. Ли Вэй. Образ Китая глазами россиян. Пекин: Peking University Press, 2016. 328 c. (на кит. языке).

3. Мэн Хуа. Сравнительное литературное воображение. Пекин: Peking University Press, 2001. 282 с. (на кит. языке).

4. Лю Яньфан. Стратегия национального имиджа Китая на фоне глобализации: исследовательская перспектива, основанная на национальных интересах. Пекин: Central Compilation and Translation Press, 2016. 265 с. (на кит. языке).

5. Ли Шоюань. Международные отношения и китайская дипломатия: уникальный ландшафт массовой коммуникации. Пекин: Beijing Broadcasting Institute Press, 1999. 317 с. (на кит. языке).

6. Гуань Вэньху. Национальная теория изображения. Чэнду: University of Electronic Science and Technology Press, 2000. 613 с. (на кит. языке).

7. Ли Яньбин. Построение национального имиджа Китая в перспективе политической коммуникации. Пекин: China Social Sciences Press, 2014. 253 с. (на кит. языке).

8. Ян Вэйфэнь. Проникновение и взаимодействие: радио, телевидение и международные отношения. Пекин: Beijing Broadcasting Institute Press, 2000. 230 с. (на кит. языке).

9. Чжан Кун. Национальная имиджевая коммуникация. Шанхай: Fudan University press, 2005. 558 с. (на кит. языке).

10. Чэн Манли. Массовые коммуникации и формирование национального имиджа // Международная журналистика. 2007. № 3. С. 5-10 (на кит. языке).

11. Галумов Э. А. Международный имидж России: стратегия формирования. М.: Известия, 2003. 446 c.

12. Сюй Сяогэ. Проблема национального имиджа в международной новостной коммуникации // Журналистика и коммуникационные исследования. 1996. № 2. С. 35-48 (на кит. языке).

13. Ли Чжи. Национальный имидж Китая: интерпретация конструктивизма в эпоху глобальной коммуникации. Пекин: Xinhua Publishing House, 2011. 153 с. (на кит. языке).

14. Тан Гуанхун. О национальном имидже // Международные исследования. 2004. № 4. C. 19-46. 
15. Хэ Хуэй, Хуан Дяньлинь, Лю Пэн. Построение национального имиджа в среде новых медиа должно соответствовать закону коммуникации // External Communication. 2007. № 7. С. 44-47 (на кит. языке).

16. Чэн Манли, Массовые коммуникации и формирование национального имиджа // Международная журналистика. 2007. № 3. С. 5-10 (на кит. языке).

17. Лю Хуэй. Формирование национального имиджа: невыносимая тяжесть массовой коммуникации // Современные коммуникации (Журнал Коммуникационного университета Китая). 2015. Том 37, № 12. С. 46-50 (на кит. языке).

18. Сяо Чуньфэн. Характеристики и мышление визуальной коммуникации национального имиджа в эпоху всех медиа // Новые медиаисследования. 2019. Том 24, № 5. С. 124-127 (на кит. языке).

19. Тихвинский С. Л. Восприятие в Китае образа России. М.: Наука, 2008. 244 с.

20. Лукин А. В. Медведь наблюдает за драконом. Образ Китая в России в XVII-XXI веках. M.: Восток-Запад: АСТ, 2007.598 с.

21. Ли Суйань. Образ России в Китае: 1949-2010. Харбин, 2012. 487 с.

22. Чжан Гуаннянь. Художественный образец современного ревизионизма: дискуссия о фильмах Григория Чухрая // Shandong Literature. 1964. № 2. С. 2-22 (на кит. языке).

23. Чжан Вэньвэй. Анализ международного статуса России после холодной войны // Журнал учительского колледжа Шанграо. 1998. № 1. С. 74-79 (на кит. языке).

24. Ши Тяньцзин. Путинская «управляемая демократия» и российские СМИ // Молодежный репортер. 2006. № 19. С. 63-65 (на кит. языке).

25. Совместное заявление РФ и КНР о развитии отношений всеобъемлющего партнерства и стратегического взаимодействия, вступающих в новую эпоху // Президент России. URL: http://www.kremlin.ru/supplement/5413 (дата обращения: 04.05.2021). 